\title{
Comparative study of combustion and emissions of diesel engine fuelled with FAME and HVO
}

This study investigates combustion and emission characteristics of a contemporary single-cylinder compression ignition engine fuelled with diesel, fatty acid methyl esters (FAME) and hydrotreated vegetable oil (HVO). These two drop-in fuels have an increasing share in automotive supply chains, yet have substantially different physical and auto-ignition properties. HVO has a lower viscosity and higher cetane number, and FAME has contrary characteristics. These parameters heavily affect mixture formation and the following combustion process, causing that the engine pre-optimized to one fuel option can provide deteriorated performance and excess emissions if another sustainable option is applied. To investigate the scale of this problem, injection pressure sweeps were performed around the stock, low $\mathrm{NO}_{x}$ and low PM engine calibration utilizing split fuel injection. The results showed that FAME and HVO prefer lower injection pressures than diesel fuel, with the benefits of simultaneous reduction of all emission indicators compared to DF. Additionally, reduction of injection pressure from $80 \mathrm{MPa}$ to $60 \mathrm{MPa}$ for biodiesels at low engine load resulted in improved brake thermal efficiency by 1 percentage point, due to reduced parasitic losses in the common rail system.

Key words: diesel engine, renewable fuels, HVO, emissions

\section{Introduction}

The limits for toxic emissions and $\mathrm{CO}_{2}$ produced by the internal combustion engines are the main challenges in the light of transport sustainability. The earlier issue is especially valid for diesel engines, which are more prone to higher emissions of particulate matters (PM) and nitrogen oxides $\left(\mathrm{NO}_{\mathrm{x}}\right)$, than they spark ignition competitors. However, the pros of diesel engines are their higher thermal efficiency and scalability. Due to these advantages, diesel engines are estimated to power about $42 \%$ of todays' passenger cars in the European Union [24]. Moreover, heavy-duty transport, including waterborne, is almost completely dominated by diesel engines. The wide use of internal combustion engines as transport power plants results in the fact that they release approximately $10 \%$ of the global gaseous emissions nowadays [21].

Assuming the typical fleet renewal intervals in the heavy-duty sector from 10 (trucks) to 25 (ship propulsion) years, the short route towards decarbonisation is the use of non-fossil fuels (obtained from biomass or waste) with minimal consumption of energy from the current mix [18]. According to the European Biodiesel Board the use of biodiesel reduces $\mathrm{CO}_{2}$ emissions by $65 \%-90 \%$ [23]. Nowadays there are two leading technologies for the production of non-fossil diesel substitutes from biomass, because of their infrastructural maturity and availability of the feedstock. Transesterification of oils using methanol, or other alcohols, is one of the methods of biofuel production. As a result of this process, fatty acid methyl esters (FAMEs) are obtained. One should note that on the worldwide biofuel market FAME has a 32\% share [25]. The hydrotreated vegetable oil (HVO) is an alternative biofuel with a rapidly growing market share, currently approximately at the level of $6 \%$. HVO like FAME can be produced from waste biomass such as animal fats and the used cooking oils. In such case, these fuels can be classified as second-generation biofuels, not competing with food production [11]. During the production of HVO and FAME natural gas is utilized, however, a comparison of carbon footprints of HVO and FAME indicates HVO as more greenhouse friendly [7].

It should be noted that the quality of FAME strongly depends on the feedstock [8], while the quality of HVO is more neutral. Therefore, HVO can be produced using various oils, e.g. rapeseed, sunflower, soy. Importantly, HVO can be produced from non-edible oils like algae, jatropha, camelina, etc. as well as from waste fats. Therefore HVO outperforms FAME in terms of the food-or-fuel dilemma [3].

Side by side to $\mathrm{CO}_{2}$ footprint, fuel effect on toxic exhaust components should be taken into consideration. Emission-wise, ideal diesel fuel should not have any C-C bonds. Such fuel hardly produces particulates. On the other side, double and triple carbon bonds are determinants for soot formation. Therefore the production of soot is chemically increased by the presence of alkynes and polycyclic aromatic hydrocarbons (PAH) in fuel Furthermore, fuel sulphur increases particulate emissions [2]. HVO is formed by solely paraffinic hydrocarbons and does not contain any sulphur. Therefore, chemically HVO is superior to mineral diesel fuel (DF) and also FAME, which has double carbon bonds.

Physically, FAME has higher viscosity than DF and higher end of distillation temperature, which poses some low-temperature issues [17]. Greater density results from high oxygen content [15], which further translate to lower calorific value and lower stoichiometric air requirement. Auto-ignition properties of FAME are similar to DF. HVO is characterized by lower viscosity and density as compared to conventional diesel fuel that shortens the evaporation time and simplifies obtaining a more homogeneous air-fuel mixture. Higher cetane number of HVO, as well as the paraffinic structure, lead to shorter ignition delay and, consequently, to prolongation of soot oxidation time.

Numerous studies shown that the use of HVO can help reduce PM emissions by $50-70 \%$, when compared to DF. 
Emissions of $\mathrm{CO}$ and unburnt hydrocarbons (UHC) are also lower by the same amount. At the same time $\mathrm{NO}_{\mathrm{x}}$ emissions are almost unaffected $[1,12,22]$. Average emission impact of FAME was reported by Demirbas [4]; $\mathrm{NO}_{\mathrm{x}}$ emissions were increased by $10 \%, \mathrm{PM}$ and $\mathrm{CO}$ emissions were decreased by $45 \%$ and UHC emissions were decreased by $65 \%$. In contrast Koszałka et al. [14] showed that comparison of DF and FAME over whole engine operating area revealed virtually no difference. There is the abundant amount of research into the effects of HVO and FAME on emissions, however much less effort is put into the isolation of the mixture formation strategies on combustion and emissions.

Liu et al. [16] compared combustion and emissions of combustion of DF and high $(60 \%)$ fractions of FAME and HVO at variable exhaust gas recirculation (EGR) rates. Combustion analysis at split injection revealed that pilot fuel of HVO ignited earlier, than in the case of DF and FAME. Main fuel combustion ran with the same rate for all three fuels. In terms of emissions, both biofuels produced approximately $30 \%$ less UHC than DF, independently of EGR rate. In case of smoke emission, DF and FAME produced similar numbers, while HVO halved the emission. Omari et al. [20] optimised EGR control strategies for pure HVO combustion and pointed out that due to higher cetane number (CN), HVO preferred cooled EGR. Recently Dimitriadis et al. [5] pointed out that due to different combustion characteristics of $\mathrm{HVO}$ it is possible to improve $\mathrm{PM}-\mathrm{NO}_{\mathrm{x}}$ trade-off by injection timing adjustment. Retard of the main injection dose enabled $20 \%$ reduction of $\mathrm{NO}_{\mathrm{x}}$ emissions, while maintaining low PM emissions, $30 \%$ below DF baseline.

The premise of the current study is based on the different physical properties of the DF and their renewable substitutes. The differences in volatilities and chemical ignition delays between fuels can require different fuel injection pressures. Therefore in this research DF, FAME and HVO sensitivities to injection pressure were compared using state of the art diesel engine.

\section{Methods}

\subsection{Fuels}

The Tested DF is a standard ultra-low sulphur diesel, according to EN590. FAME was obtained from coldpressed rapeseed oil, trans-esterified at laboratory conditions. The process conditions were adjusted to meet the European norm for biofuels (EN 14214). HVO comes from the fuel company Neste Oil, and as meeting the EN590 standard is commercially available for on-road transport, as Neste Renewable Diesel [6]. Note that HVO tested here is lubricity improved. Neither DF nor HVO contained any FAME

Significant physicochemical parameters of the tested fuels are summarized in Table 1. Data for HVO are courtesy of VEBIC fuel laboratory (University of Vaasa) Finland, while FAME and DF were characterized in the fuel laboratory of Lublin University of Life Sciences. All fuels are analysed according to EN 590, EN 14214 and other related standards.
Table 1. Fuel properties

\begin{tabular}{|l|c|c|c|c|}
\hline Parameter & Unit & DF & FAME & HVO \\
\hline Density @ $15^{\circ} \mathrm{C}$ & $\mathrm{g} / \mathrm{ml}$ & 0.837 & 0.882 & 0.764 \\
\hline Viscosity @ $40^{\circ} \mathrm{C}$ & $\mathrm{mm}^{2} / \mathrm{s}$ & 2.94 & 4.43 & 2.88 \\
\hline Lower heating value & $\mathrm{MJ} / \mathrm{kg}$ & 42.8 & 38.3 & 43.7 \\
\hline Stoichiometric air demand & $\mathrm{kg} / \mathrm{kg}$ & 14.73 & 13.7 & 15.14 \\
\hline Cetane number $(\mathrm{CN})$ & - & 54.1 & 55.2 & 74.5 \\
\hline Cold filter plugging point & ${ }^{\circ} \mathrm{C}$ & -22 & -11 & -44 \\
\hline Flash point & ${ }^{\circ} \mathrm{C}$ & 70.5 & 165 & 66.3 \\
\hline Lubricity @ $60^{\circ} \mathrm{C}$ & $\mu \mathrm{m}$ & 406 & 190 & 344 \\
\hline C/H ratio & $\mathrm{kg} / \mathrm{kg}$ & 6.4 & 7.7 & 5.5 \\
\hline Sulphur content & $\mathrm{mg} / \mathrm{kg}$ & 6.1 & 1 & $<1$ \\
\hline Ash content & $\% \mathrm{wt}$. & 0.014 & 0.01 & 0.002 \\
\hline
\end{tabular}

The differences between the tested fuels highlighted in the introduction are confirmed in Table 1. HVO has a significantly higher $\mathrm{CN}$ value, which affects the auto-ignition properties. Thanks to slightly lower viscosity, HVO also boasts better spraying properties. Note that FAME has over $50 \%$ higher viscosity compared to HVO or DF. It should be emphasized that the significantly better low-temperature properties of HVO in relation to DF result in a lower flashpoint.

When analysing the properties of fuels, resulting from the composition of the mixture, it can be noticed that the LHV values for DF and HVO are similar and amount to about $43 \mathrm{MJ} / \mathrm{kg}$. FAME, on the other hand, has much lower LHV, which is however compensated by lower air demand. The mass ratio of carbon to hydrogen $(\mathrm{C} / \mathrm{H})$ is in favour of HVO. It determines cleaner combustion in terms of tank-towheel $\mathrm{CO}_{2}$ emissions. The undoubted advantage of $\mathrm{HVO}$ and FAME is the total content of pollutants an order of magnitude lower than in the case of DF, thus potentially reducing $\mathrm{SO}_{\mathrm{x}}$ and $\mathrm{PM}$ emissions.

\subsection{Engine test stand}

The engine test stand at Lublin University of Technology is particularly suitable for end-use validation of alternative fuels. The single-cylinder research engine (AVL 5402 CR DI) is the heart of the research platform. The engine's displacement is $510 \mathrm{~cm}^{3}$, at a $17: 1$ compression ratio. The combustion chamber is toroidal in shape, while the valves, including the dedicated swirl port (AVL-LEADER concept), are angled at $3.5^{\circ}$. The fuel is supplied via a Bosch CP4.1 high-pressure common rail system equipped with a seven-hole electromagnetic injector. Etas INCA software is used to supervise a fully open Bosch engine control unit. Figure 1 shows the instrumented test stand, while Table 2 summarizes the basic engine parameters.

All measurements in this research are performed in steady-state conditions. To ensure that the system is thermally stable and to minimize the influences of external disturbances on measurement results, various conditioning measures are applied. The fuel consumption is measured gravimetrically, with the AVL 733S dynamic fuel meter and the fuel is thermally conditioned via the corresponding AVL 753C fuel temperature conditioner. Thermal conditioning is also applied to the coolant and lubricant circuits. The in-house system maintains the desired temperature of both media with $0.5^{\circ} \mathrm{C}$ accuracy, regardless of the operating point. 


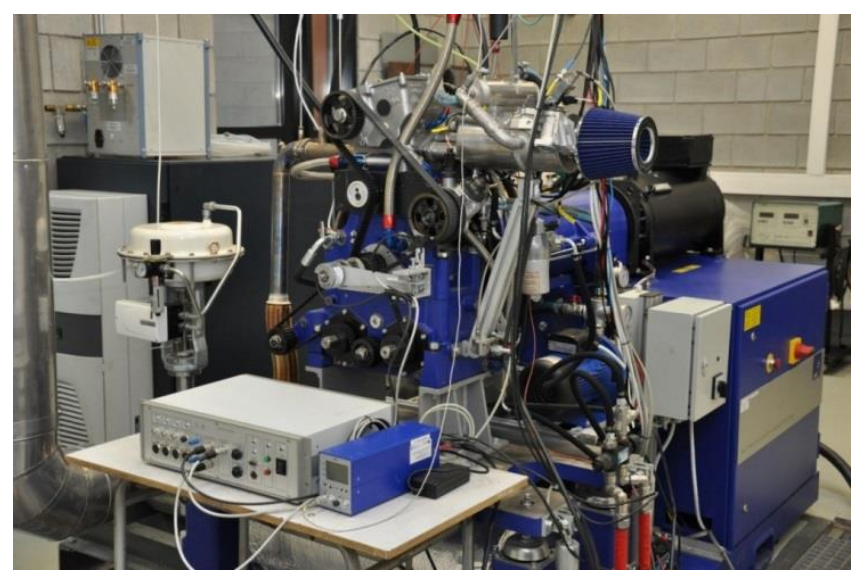

Fig. 1. Engine research test stand at Lublin University of Technology

Table 2. Parameters of the research engine

\begin{tabular}{|l|c|}
\hline Type & AVL 5402 \\
\hline Configuration & Four-stroke, single-cylinder \\
\hline Bore & $85 \mathrm{~mm}$ \\
\hline Stroke & $90 \mathrm{~mm}$ \\
\hline Displacement & $510.5 \mathrm{~cm}^{3}$ \\
\hline Compression ratio & $17: 1$ \\
\hline No. of valves & 4 \\
\hline Combustion type & Direct injection \\
\hline Max. fuel pressure & $180 \mathrm{MPa}$ \\
\hline Injection system & Common rail CP4.1 \\
\hline Engine management & AVL-RPEMS, ETK7-Bosch \\
\hline
\end{tabular}

On the intake side, the research stand is equipped with an electrically-driven Roots compressor (up to 2 bar boost pressure) with a controllable charge air cooler. On the exhaust, side the backpressure control, realised by a proportional butterfly valve, mimics turbocharger operation. The engine has both high- and low-pressure EGR systems, where the latter is equipped within the Roots blower. Note that neither boost nor EGR is used in the current experiment. The intake air flow rate is measured with a mass flow meter. Using the Bosch LSU 4.2 lambda probe and the ETAS LA4 lambda sensor, the excess air coefficient $(\lambda)$ is calculated with pressure compensation [13].

Low-frequency transducers mounted on the intake manifold, exhaust manifold, EGR path, cooling and lubrication systems, provide information on the thermal state of the entire system. All the above-described measurement and control functionalities are governed by an in-house test bench management/data acquisition system.

The present research further utilizes the benefits of detail combustion and emission analysis. The first functionality is based on instantaneous in-cylinder pressure measurement, provided by the AVL GU22C piezo-electric transducer installed in the cylinder head. The transducer is connected to the indication system via the compatible charge amplifier and an optical encoder is used to trigger pressure measurement every $0.1^{\circ}$ crank angle (CA).

AVL SESAM multi-component gas analyzer is used to determine the concentration of individual exhaust gas components. The measurement incorporates Fourier Transform Infrared (FTIR) technique and enables over 20 legislated and unlegislated exhaust gas components to be characterized simultaneously. The concentration of particulates is measured separately using the Maha MPM-4 analyser.

\subsection{Experimental conditions and procedures}

The tests are carried out for a single mid-load operating point with net IMEP 0.5 MPa. The fuel value is adjusted to keep the load constant, across all the parameter sweeps, irrespectively to the fuel used. In this campaign, the engine is operated naturally aspirated and without external EGR. At these conditions excess air ratio $\lambda$ is close to 2.2, however, varying slightly to satisfy the constant load condition.

The engine speed was kept fixed at $1500 \mathrm{rpm}$. The engine coolant and lubricating oil temperatures were independently conditioned to $85^{\circ} \mathrm{C}$. The temperature in the fuel entering the high-pressure pump is also fixed at $30^{\circ} \mathrm{C}$.

The rail pressure is set according to a predefined engine control map to $80 \mathrm{MPa}$. For each fuel, this parameter was swept $\pm 20 \mathrm{MPa}$, pertaining to the goal of the present study. Note that the fuel is injected using a multi-pulse injection scheme, where approximately $12 \%$ of the total fuel value accounts for an early pilot with the start of injection (SOI) at $20^{\circ} \mathrm{CA}$ before the top dead centre (bTDC). The remaining (main) pulse is commenced at $\mathrm{SOI}=8^{\circ} \mathrm{CA}$ bTDC.

The recorded in-cylinder pressure data is pegged, filtered and averaged over 100 cycles. The pressure signal is further subjected to a standard first-law heat release analysis, with correction for convective heat loss through cylinder walls (Hohenberg heat transfer model). The calculations are supported by AVL Boost software, to accommodate for detail cylinder mass flow rate estimation.

Slow-changing quantities, such as fuel consumption and emissions, are averaged in individual measurement points of the campaign, over a standard 60-second window, to satisfy the steady-state measurement principle. Since the current study investigated single operating point with roughly constant in-cylinder air value, emission factors are analysed as concentrations on a mole basis - pertaining to the direct output of respective emission analysers.

\section{Results and discussion}

\subsection{Effects of fuels on combustion}

We open up the discussion of the results with a benchmark of tested fuels at baseline conditions i.e. at $80 \mathrm{MPa}$ rail pressure. In this respect, it is critical to consider differences in combustion as a driving force to emission formation. Without any detailed analysis, it can be noted that the combustion of the three fuels runs similarly, however only if the main, diffusion-controlled combustion phase is considered. This phase corresponds to the third, dominant peak on the heat release rate (HRR) presented in Fig. 2. The insensitivity is driven by the phenomenology of the multipulse combustion concept realised. Namely, the primarily premixed pilot combustion, visible as the first two characteristics peaks, HRRs (respectively, cool flames and negative temperature coefficient reactions followed by the hightemperature premixed phase), acts as a primer towards the main injection. The main injection pulse ignites instantly after reaching the hot burnt zone of the pilot, located near the combustion chamber walls. Therefore, the similarity results from the fact that fuel-to-fuel viscosity differences reported in Table 1, are too small to cause significant differences in spray penetration lengths. 


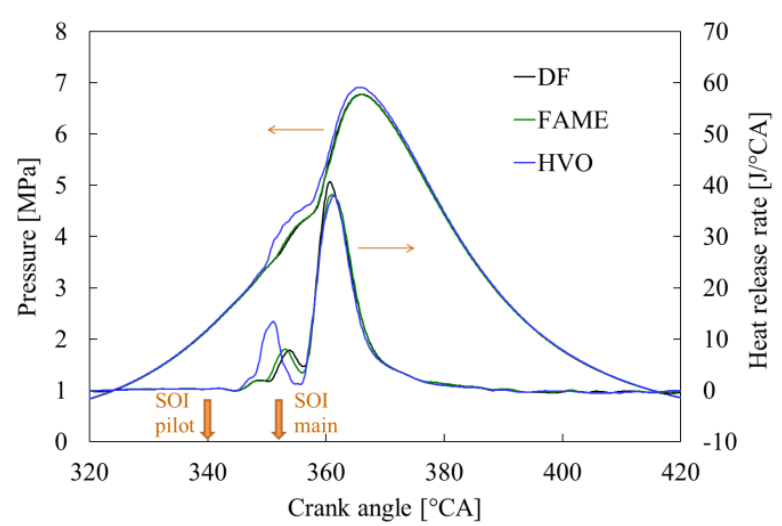

Fig. 2. In-cylinder pressures and HRRs for investigated fuels at $80 \mathrm{MPa}$ rail pressure

The higher CN of HVO manifests in ignition characteristics of the pilot, which is notably different compared to both DF and FAME. Namely, the high-temperature combustion of the pilot fuel starts approximately $2{ }^{\circ} \mathrm{CA}$ earlier for HVO. Moreover, the HRR drop to a constant, near-zero value, between $354.5^{\circ} \mathrm{CA}$ and $356^{\circ} \mathrm{CA}$, indicates that the $\mathrm{HVO}$ pilot is completely burnt before the main fuel starts to burn. The more complete oxidation of the pilot translates into an increase of the in-cylinder pressure before TDC, as evident for HVO in Fig. 2. It should be noted that the combustion characteristics of FAME and DF are very similar. However, slightly advanced pilot fuel combustion of FAME is visible.

A superposition of the combustion characteristics derived from Fig. 2 in this section, with physical properties of individual fuels, discussed in Table 1, allows concluding that even large-scale differences in viscosity (roughly $70 \%$ between FAME and DF) have an indirect effect on combustion in the considered multi-pulse injection strategy. The fuels $\mathrm{CN}$ shapes the premixed pilot combustion, which forms a direct trigger for the main phase.

\subsection{Effects of fuel pressure on combustion}

The combustion analysis from section 3.1 forms the background for understanding the response of the fuels to changes in injection pressure. These responses concerning HRR are shown in Fig. 3, for DF, FAME and HVO respectively.

Increasing the injection pressure in principle manifests in (i) reducing the pilot HRR and (ii) increasing the main HRR. Let's discuss these effects one by one based on the DF reference, following with fuel-to-fuel differences.

Concerning the first effect, the pilot heat release diminishes cumulatively - less fuel is burnt during the pilot stage while elevating the injection pressure from 80 to $100 \mathrm{MPa}$. This indicates a potential wall-wetting effect while injecting and early pilot with higher spray penetration velocities (direct effect of elevated injection pressure). Interesting is the fact that reducing the rail pressure from 80 to $60 \mathrm{MPa}$ does not cause a further increase in the pilot HRR but, what is evident in the case of HVO, can even slightly decrease the amount of pilot fuel burnt. This non-monotonic response of pilot combustion to injection pressure indicates that there is another mechanism involved. Mapping the HRR results from Fig. 3 with physicochemical properties of subsequent fuels does not reveal any particular relationship, however.
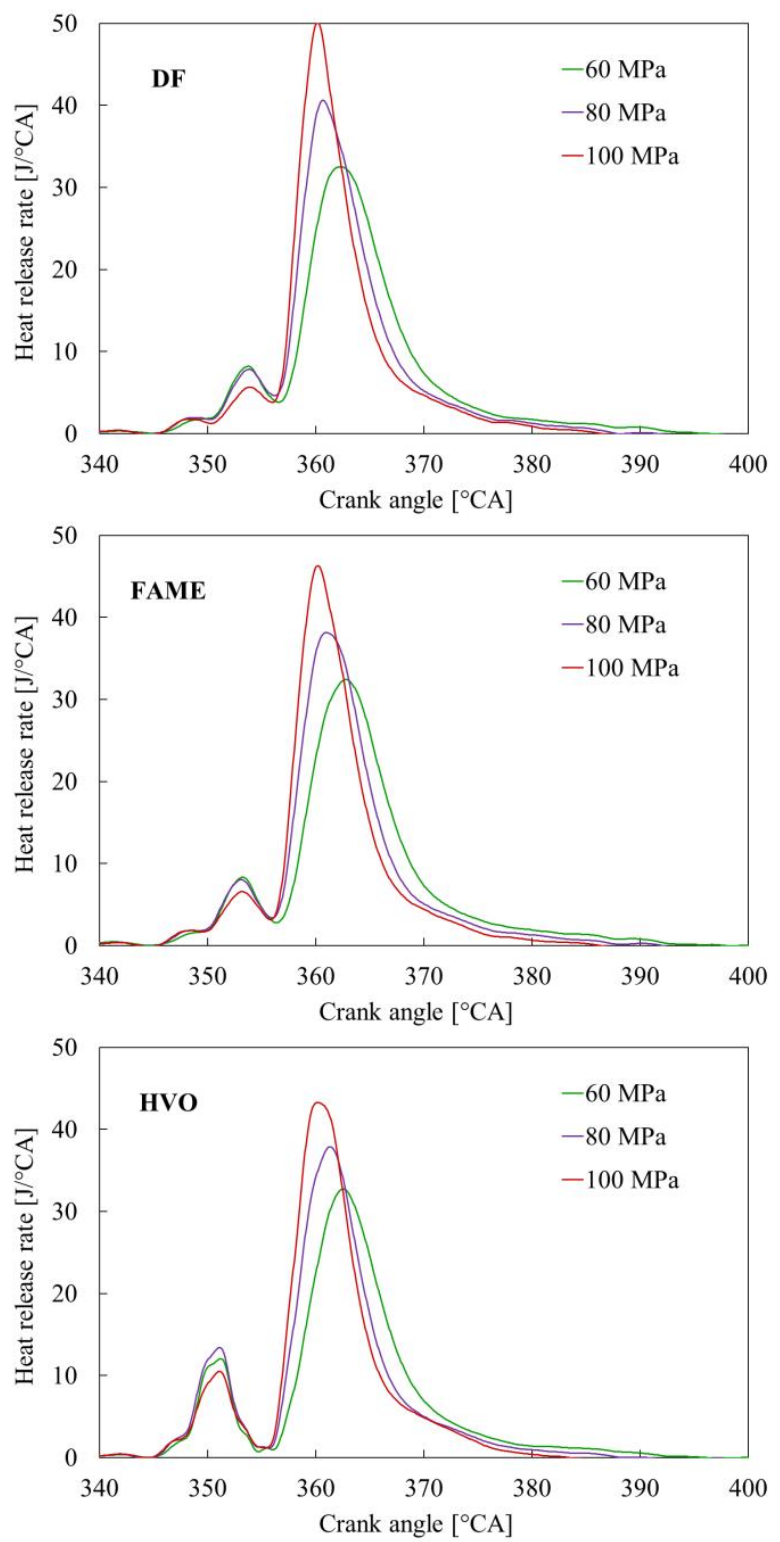

Fig. 3. HRRs for investigated rail pressures and for DF, FAME and HVO

As far as there is some ambiguity in the injection pressure effect on the pilot combustion, the influence of this calibration parameter on the main combustion phase is transparent from Fig. 3. Elevating injection pressure makes the main HRR more rapid and this combustion phase tends to start earlier. The more rapid combustion is invoked by the fact that with elevated injection pressure the main spray reaches the pilot burn zone faster when the premixed combustion is still in progress. The main combustion hence has more favourable conditions to progress within a hotter, more reactive, and oxygen richer environment of the developing premixed flame. Note that the higher main peak HRRs at elevated injection pressure are additionally reinforced by better fuel atomization within the main spray. Finally, there are evident couplings between the amount of heat released in the pilot phase, and how the main combustion proceeds. For cases in which elevated injection pres- 
sure causes the wall-wetting affected reduction of pilot HRR, the accumulated hydrocarbons are partially picked-up by the main combustion adding to the cumulative heat released in this phase. The cases with reduced pilot HRR also partially balance-out the combustion-accelerating effect of faster main spray propagation. As a result, the main HRRs for $80 \mathrm{MPa}$ and $100 \mathrm{MPa}$ start roughly at the same CA.

These effects related to the main combustion are evident for all tested fuels, as visible in Fig. 3. The magnitude of those effects depends however on how the pilot combustion develops - not particularly on fuel properties directly. Hence, for instance, DF exhibits by far the highest sensitivity to injection pressure - attributed to the fact that elevated rail pressure deteriorates the pilot combustion the most and that the two combustion phases are closely coupled (minimum dwell between the pilot and main HRR). According to the same logic in the case of HVO, where the combustion phases are clearly separated, the relative changes in pilot HRR affect the main combustion to the least extent.

\subsection{Effects of fuel pressure on emissions}

Assessing the fuel's emission performance in Fig. 4 shows that, independently of fuel pressure, HVO and FAME have a better $\mathrm{PM} / \mathrm{NO}_{\mathrm{x}}$ trade-off. Namely, both biofuels roughly halved PM emissions when compared to DF. At the same time, biofuels produce only 2-3\% higher $\mathrm{NO}_{\mathrm{x}}$ emissions. The propensity of the fuel to create PM seems to correlate to the sulphur and ash content (refer to Table 1). Fuel-bound sulphur is known to form a good nesting for particulates formation [19]. Its oxidation products $\left(\mathrm{SO}_{3}\right.$ particularly) bind with water to sulfuric acid which condenses to soot when exhaust gasses cool down. Hence, HVO with the lowest level of contaminants produces the least PM.

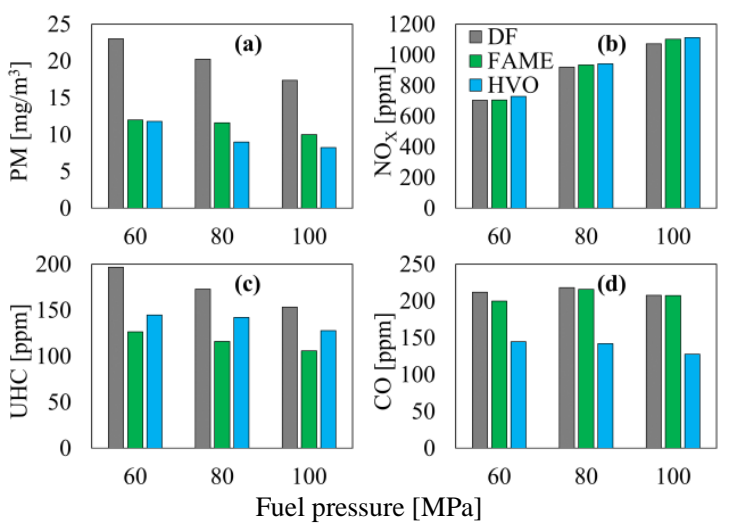

Fig. 4. Concentrations of major legislative emission components for DF, FAME and HVO; rail pressure sweep

FAME, due to fuel-bound oxygen is known to produce more $\mathrm{NO}_{\mathrm{x}}$ compared to its unoxygenated counterparts [9, 10]. Interestingly, however, this has not been confirmed in this study, suggesting that local oxygen availability is not limiting the $\mathrm{NO}_{\mathrm{x}}$ formation and the mechanism is predominantly thermal-driven.

Biofuels ultimately burn more completely than DF. Cumulative CO and UHC emissions are around 25-30\% in favour of both fuels, while $\mathrm{HVO}$ exerts lower $\mathrm{CO}$ emissions than FAME. The trend in UHC is the opposite.
In the light of largely similar combustion behaviour of DF, HVO and FAME (Fig. 2), the above-discussed fuel to fuel differences in emissions are resulting directly from physicochemical properties. According to Fig. 4 these fuelspecific emissions are maintained thought the injection pressure sweep. The effects here are rather straightforward. Elevated injection pressure reduces PM and UHC emissions due to better fuel atomization and increased in-cylinder turbulence. Both mechanisms support more complete oxidation. The fuel wetting during pilot combustion, at elevated rail pressure is not evident through emissions results, suggesting that main combustion successfully after-burns potential residues from the pilot.

$\mathrm{NO}_{\mathrm{x}}$ emission increases with injection pressure and this effect can be attributed directly to changes in the HRR rate observed in Fig. 3. Namely, more rapid main combustion yields higher peak temperatures, intensifying Zeldovich reactions responsible for $\mathrm{NO}_{\mathrm{x}}$ formation.

\subsection{Discussion}

Comparison of the three tested fuels in Fig. 4 shows that all toxic exhaust gas components, except $\mathrm{NO}_{\mathrm{x}}$ increase when fuel pressure is reduced. However, the baseline levels of PM and UHC for biofuels are much lower than for DF. Assuming the PM limit as given by DF reference, it is reasonable to reduce injection pressure if biofuels are considered. Reducing injection pressure from baseline $80 \mathrm{MPa}$ to $60 \mathrm{MPa}$ cuts down $\mathrm{NO}_{\mathrm{x}}$ by $20 \%$ while for HVO and FAME PM is still over $30 \%$ lower compared to DF baseline. Assuming the slightly retarded combustion onset, resulting from this measure (Fig. 3), thermal efficiency can be further optimized with the main injection timing. Therefore, reduction of injection pressure, enabled by wider emission tolerances of FAME and HVO, can be essential for maximizing overall engine efficiency.

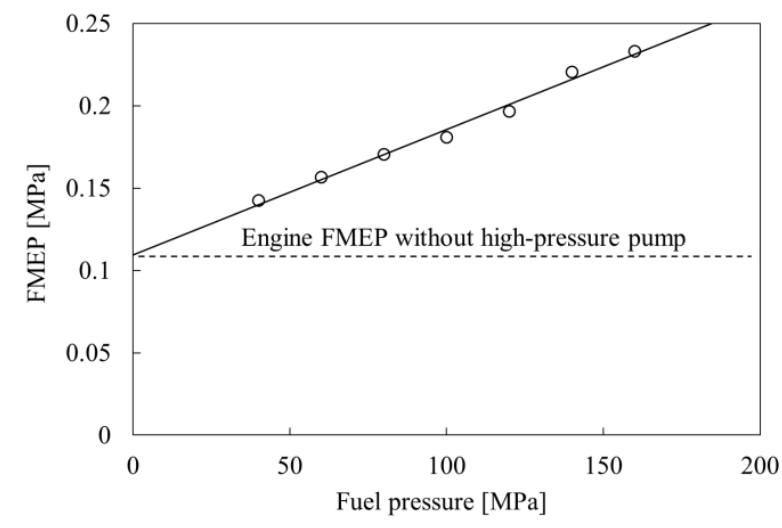

Fig. 5. Effect of fuel pressure on friction mean effective pressure of the engine at constant IMEP of $0.5 \mathrm{MPa}$; DF reference

Discussion of Fig. 5 explains this issue on the basis of engine friction losses, expressed here in the units of friction mean effective pressure (FMEP). FMEP is obtained by subtracting the brake mean effective pressure (BMEP), measured on the engine dyno, from IMEP, calculated from in-cylinder pressure.

You can note that, at the given operating point, the pressure-dependent parasitic losses of the common-rail fuel pump can form up to $50 \%$ of the overall engine friction 
losses. To this end, reducing fuel pressure from $80 \mathrm{MPa}$ to $60 \mathrm{MPa}$ cuts down mechanical losses by $11 \%$, which translates to roughly $1 \%$ of the total fuel consumption.

Finally, note that the particularly low heating value of FAME (Table 1) translates to additional injection pump expenditure - hence larger parasitic losses. The effect is however order of magnitude smaller and remains practically unnoticeable on the scale of Fig. 5.

\section{Conclusion}

Within the boundaries of the discussed combustion regime, the fuel cetane number has a dominant effect on fuels combustion performance, affecting pilot fuel combustion. Due to the strong coupling of the main combustion with the early pilot, the main combustion remains largely insensitive to changes in fuel, hence all react to injection pressure similarly.

Despite large-scale differences in viscosity and flashpoint between tested fuels, the effect of all other fuel parameters on combustion is an order of magnitude lower than that of cetane number. The present scope of experiments ultimately fails to decouple those secondary effects. Such decoupling is however desired and for that, future research should involve tailor-made fuels with large-scale differences only in individual physicochemical parameters.

The oxygenated nature of FAME and its large viscosity ultimately do not deteriorate emissions in the realized combustion concept. The fuel-to-fuel differences result directly from sulphur and ash content in the fuel, rather than from different combustion characteristics. Hence, HVO and FAME exhibit a more favourable $\mathrm{PM} / \mathrm{NO}_{\mathrm{x}}$ trade-off than DF. These more favourable biofuel characteristics allow reduction of injection pressure from baseline 80 to $60 \mathrm{MPa}$ while being superior in all emission factors and brake efficiency. Injection pressure-optimized, emissions from FAME and HVO were similar, and respectively $20 \%$ and $40 \%$ lower in terms of $\mathrm{NO}_{\mathrm{x}}$ and PM, compared to dieseloptimized conditions.

\section{Acknowledgements}

The authors wish to thank AVL List GmbH for making the simulation software available within a framework of the AVL University Partnership Program.

The authors wish to thank researchers form VEBIC Fuel Laboratory for HVO fuel delivery and analyses.

\section{Nomenclature}

BMEP brake mean effective pressure

bTDC before the top dead centre

$\mathrm{C} / \mathrm{H}$ mass ratio of carbon to hydrogen

$\mathrm{CA}$ crank angle

$\mathrm{CN}$ cetane number

$\mathrm{CO}$ carbon monoxide

$\mathrm{CO}_{2}$ carbon dioxide

DF diesel fuel

EGR exhaust gas recirculation

FAME fatty acid methyl esters

FMEP friction mean effective pressure
FTIR Fourier Transform Infrared

HRR heat release rate

HVO hydrotreated vegetable oil

IMEP indicated mean effective pressure

LHV lower heating value

$\mathrm{NO}_{\mathrm{X}} \quad$ nitrogen oxides

PM particulate matters

SOI start of injection

$\mathrm{SO}_{\mathrm{X}} \quad$ sulfur oxides

UHC unburnt hydrocarbons

\section{Bibliography}

[1] AATOLA, H., LARMI, M., SARJOVAARA, T. et al. Hydrotreated Vegetable Oil (HVO) as a renewable diesel fuel: trade-off between $\mathrm{NO}_{\mathrm{x}}$, particulate emission, and fuel consumption of a heavy duty engine. SAE International Journal of Engines. 2008, 1, 1251-1262. https://doi.org/10.4271/2008-01-2500

[2] BAE, C., KIM, J. Alternative fuels for internal combustion engines. Proceedings of the Combustion Institute. 2017, 36(3), 3389-3413.

https://doi.org/10.1016/j.proci.2016.09.009

[3] BEZERGIANNI, S., DIMITRIADIS, A. Comparison between different types of renewable diesel. Renewable and Sustainable Energy Reviews. 2013, 21, 110-116. https://doi.org/10.1016/j.rser.2012.12.042

[4] DEMIRBAS, A. Progress and recent trends in biodiesel fuels. Energy Conversion and Management. 2009, 50, 1434. https://doi.org/10.1016/j.enconman.2008.09.001

[5] DIMITRIADIS, A., SELJAK, T., VIHAR, R. et al. Improving $\mathrm{PM}-\mathrm{NO}_{\mathrm{x}}$ trade-off with paraffinic fuels: A study towards diesel engine optimization with HVO. Fuel. 2020, 265, 116921. https://doi.org/10.1016/j.fuel.2019.116921

[6] Engine Technology International. March 2021, 60-61.
[7] GARRAÍN, D., HERRERA, I., LAGO, C. et al. Renewable diesel fuel from processing of vegetable oil in hydrotreatment units: theoretical compliance with European Directive 2009/28/EC and ongoing projects in Spain. 2010, 4. https://doi.org/10.4236/sgre.2010.12011

[8] GOLIMOWSKI, W., BERGER, W.A., PASYNIUK, P. et al. Biofuel parameter dependence on waste fats' fatty acids profile. Fuel. 2017, 197, 482-487. https://doi.org/10.1016/j.fuel.2017.02.067

[9] GOLIMOWSKI, W., KRZACZEK, P., MARCINKOWSKI, D. et al. Impact of biogas and waste fats methyl esters on $\mathrm{NO}, \mathrm{NO}_{2}, \mathrm{CO}$, and $\mathrm{PM}$ emission by dual fuel diesel engine. Sustainability. 2019, 11(6), 1799. https://doi.org/10.3390/su11061799

[10] GRACZ, W., CZECHLOWSKI, M., MARCINKOWSKI, D. et al. The impact of the temperature of rapeseed oil methyl esters on nitrogen oxides emissions. E3S Web of Conferences. 2020, 171, 01002. https://doi.org/10.1051/e3sconf/202017101002

[11] GRZELAK, P., ŻÓŁTOWSKI, A. Environmental assessment of the exploitation of diesel engines powered by biofuels. Combustion Engines. 2020, 180(1), 31-35. https://doi.org/10.19206/CE-2020-105 
[12] HUNICZ, J., MATIJOŠIUS, J., RIMKUS, A. et al. Efficient hydrotreated vegetable oil combustion under partially premixed conditions with heavy exhaust gas recirculation. Fuel. 2020, 268, 117350.

https://doi.org/10.1016/j.fuel.2020.117350

[13] KASPRZYK, P., HUNICZ, J., RYBAK, A. et al. Excess air ratio management in a diesel engine with exhaust backpressure compensation. Sensors. 2020, 20(22), 6701. https://doi.org/10.3390/s20226701

[14] KOSZAŁKA, G., HUNICZ, J., NIEWCZAS, A. A comparison of performance and emissions of an engine fuelled with diesel and biodiesel. SAE International Journal of Fuels and Lubricants. 2010, 3, 77-84. https://doi.org/10.4271/2010-011474

[15] KRZACZEK, P., RYBAK, A., BOCHNIAK, A. The impact of selected biofuels on the performance parameters of the common rail power system in the utility engine. MATEC Web of Conferences. 2018, 234, 03004. https://doi.org/10.1051/matecconf/201823403004

[16] LIU, D., GHAFOURIAN, A., XU, H. Phenomenology of EGR in a light duty diesel engine fuelled with hydrogenated vegetable oil (HVO), used vegetable oil methyl ester (UVOME) and their blends. SAE Technical Paper 2013-011688. 2013. https://doi.org/10.4271/2013-01-1688

[17] MARCINKOWSKI, D., RUKOWICZ, B., GOLIMOWSKI, W. et al. Effect of selected depressants on cold filter plugging point for methyl esters obtained from transesterification of waste vegetable and animal fats. Przemyst Chemiczny. 2017, 96(9), 1927-1930.

https://doi.org/10.15199/62.2017.9.22

\begin{abstract}
Jacek Hunicz, DSc., DEng. - Faculty of Mechanical Engineering, Lublin University of Technology.

e-mail:j.hunicz@pollub.pl
\end{abstract}

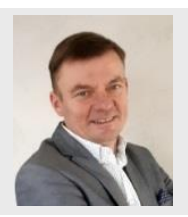

Paweł Krzaczek, DEng. - Faculty of Production Engineering, University of Life Sciences. e-mail: pawel.krzaczek@up.lublin.pl
[18] MIKULSKI, M., AMBROSEWICZ-WALACIK, M., HUNICZ, J. et al. Combustion engine applications of waste tyre pyrolytic oil. Progress in Energy and Combustion Science. 2021, 85, 100915 .

https://doi.org/10.1016/j.pecs.2021.100915

[19] NEEFT, J.P.A., MAKKEE, M., MOULIJN, J.A. Diesel particulate emission control. Fuel Processing Technology. 1995, 47(1), 1-69. https://doi.org/10.1016/0378-3820(96)01002-8

[20] OMARI, A., PISCHINGER, S., BHARDWAJ, O.P. et al. Improving engine efficiency and emission reduction potential of HVO by fuel-specific engine calibration in modern passenger car diesel applications. SAE International Journal of Fuels and Lubricants. 2017, 10(3), 756-767. https://doi.org/10.4271/2017-01-2295

[21] REITZ, R.D., OGAWA, H., PAYRI, R. et al. IJER editorial: The future of the internal combustion engine. International Journal of Engine Research. 2020, 21(1), 3-10. https://doi.org/10.1177/1468087419877990

[22] SUGIYAMA, K., GOTO, I., KITANO, K. et al. Effects of hydrotreated vegetable oil (HVO) as renewable diesel fuel on combustion and exhaust emissions in diesel engine. $S A E$ International Journal of Fuels and Lubricants. 2011, 5, 205215. https://doi.org/10.4271/2011-01-1954

[23] www.ebb-eu.org/biodiesel.php. On-line access: 02.2021.

[24] www.eea.europa.eu/data-and-maps/daviz/dieselisation-ofdiesel-cars-in-4\#tab-chart_1. On-line access: 02.2021.

[25] www.ifpenergiesnouvelles.com/article/biofuels-dashboard2019. On-line access: 02.2021.
Arkadiusz Rybak, MEng. - Faculty of Mechanical Engineering, Lublin University of Technology.

e-mail:a.rybak@pollub.pl

Maciej Mikulski, DEng. - School of Technology and Innovation, Energy Technology, University of Vaasa.

e-mail:maciej.mikulski@uwasa.fi
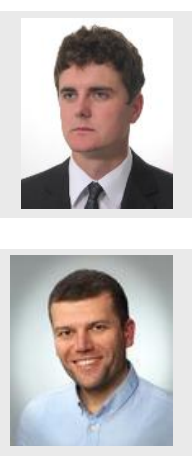

Michał Gęca, MEng. - Faculty of Mechanical Engineering, Lublin University of Technology.

e-mail: michal.geca@pollub.pl
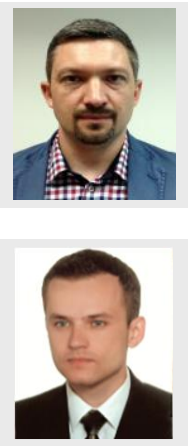